Br Heart $\mathcal{F}$ 1986;56:327-33

\title{
Left ventricular dysfunction in patients with angina pectoris and normal coronary angiograms
}

\author{
P M SCHOFIELD, N H BROOKS, D H BENNETT \\ From the Regional Cardiac Centre, Wythenshawe Hospital, Manchester
}

SUMMARY Left ventricular function was assessed in 201 patients who presented with angina pectoris and who were subsequently found to have completely normal coronary angiograms. Left ventricular angiograms from 187 patients were suitable for analysis of systolic regional wall motion; 121 were found to be normal and 66 had a total of 115 hypokinetic segments. Patients with hypokinesia had a significantly higher left ventricular end systolic volume and a significantly. lower left ventricular ejection fraction and exercise capacity than those in whom regional wall motion was normal. Thirty one per cent of patients with normal wall motion and $30 \%$ of those with hypokinesia had a resting left ventricular end diastolic pressure $>15 \mathrm{~mm} \mathrm{Hg}$. There were significantly more smokers in the group with hypokinetic segments.

Thus of patients with angina and normal coronary angiograms, 25\% had evidence of left ventricular systolic dysfunction, $20 \%$ had evidence of diastolic dysfunction, and $11 \%$ had evidence of both systolic and diastolic dysfunction. The results suggest that smoking may be associated with left ventricular regional wall motion abnormalities.

The occurrence of angina pectoris despite normal coronary angiograms is a common clinical problem $^{12}$ that is frustrating for both the patient and physician. Some investigators have suggested that in many of these patients the cause of the pain is non-cardiac. Oesophageal ${ }^{34}$ and psychosomatic ${ }^{5}$ causes have been suggested. Others, however, have shown that many of these patients have abnormal exercise electrocardiograms, ${ }^{67}$ abnormal lactate metabolism during infusion of isoprenaline or atrial pacing, ${ }^{89}$ and reduced coronary vasodilator reserve. ${ }^{10}$ Richardson et al in 1974 reported seven patients with angina and normal coronary angiograms in whom endomyocardial biopsy specimens showed features of congestive cardiomyopathy. ${ }^{11}$ More recently radionuclide angiography has been used to show that some patients with chest pain and normal coronary arteries have left ventricular dysfunction during exercise. ${ }^{1213}$

We have studied a large group of patients presenting with typical angina pectoris who had

Requests for reprints to Dr P M Schofield, Cardiology Area B, Wythenshawe Hospital, Southmoor Road, Wythenshawe, Manchester M239LT.

Accepted for publication 11 June 1986 completely normal coronary angiograms. The study was designed to assess systolic and diastolic left ventricular function and to relate these variables to clinical features and the results of non-invasive investigations.

\section{Patients and methods}

\section{PATIENT POPULATION}

Two hundred and one patients (99 men and 102 women aged 27-64 (mean 45.4) years) with angina pectoris were found to have normal coronary angiograms when they were studied at the regional cardiac unit between July 1981 and June 1984. Unlike many previous studies, we did not include patients with even minor irregularities on the coronary arteriogram. We also excluded patients with variant angina, atypical chest pain, hypertrophic obstructive cardiomyopathy, uncontrolled hypertension, important valvar heart disease, or clinical or radiological evidence of cardiac failure.

\section{HISTORY AND EXAMINATION}

The history was taken independently by at least two members of the cardiac unit. The presence or absence of five features of chest pain was noted: site 
(retrosternal, with and without left chest pain), character (constricting, gripping, pressing), radiation (left arm, shoulder, neck, jaw), usual precipitating factors (exercise, emotion, cold weather), and usual relieving factors (relief within 10 minutes of resting or taking glyceryl trinitrate).

The presence or absence of five risk factors was also noted. Patients were classified as smokers if they had smoked at least 40 cigarettes per week for at least 10 years. ${ }^{14} \mathrm{~A}$ diastolic blood pressure that had been consistently $>100 \mathrm{~mm} \mathrm{Hg}$ was regarded as evidence of systemic hypertension, although only patients who became normotensive on treatment were included in the study. The presence of diabetes mellitus (treated with diet, oral hypoglycaemics, or insulin) and a family history of ischaemic heart disease $^{14}$ (angina or myocardial infarction in parents, grandparents, or siblings) were determined. Patients were regarded as being overweight if they were at least $15 \%$ above the mean weight for their height and sex. ${ }^{15}$

\section{ELECTROCARDIOGRAPHY AND EXERCISE TESTING}

A standard 12 lead electrocardiogram was obtained in all 201 patients, none of whom were being treated with digoxin. Symptom limited treadmill exercise testing was performed according to a standard Bruce protocol. The development of chest pain during exercise, and exercise capacity as percentage of the predicted normal value for their age and $\operatorname{sex}^{16}$ were noted. ST segment depression ( $\geqslant 1 \mathrm{~mm}$ from resting values for horizontal or downsloping depression or $\geqslant 2 \mathrm{~mm}$ for upsloping depression) that developed $0.08 \mathrm{~s}$ after the $\mathrm{J}$ point was regarded as abnormal. ${ }^{17}$

\section{CARDIAC CATHETERISATION}

Selective coronary angiography was performed in multiple views in all patients. Resting left ventricular end diastolic pressure was measured before

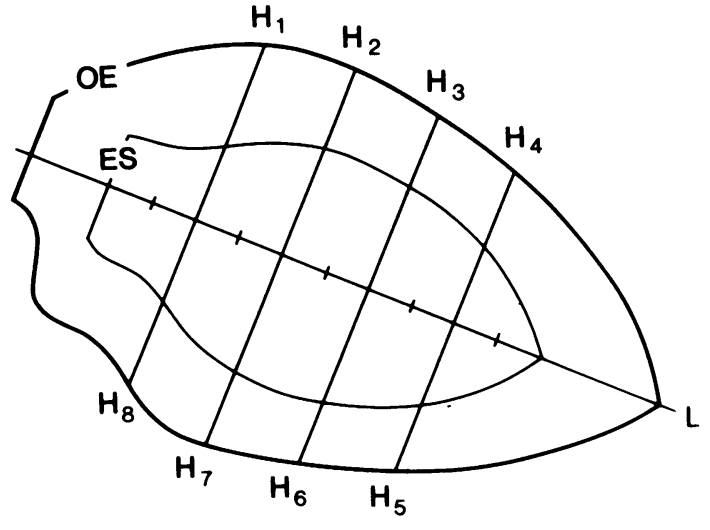

Fig 1 Ventricular silhouettes at onset of ejection (OE) and at end systole $(E S)$. The hemiaxes $\left(H_{1-8}\right)$ divide the end systolic longitudinal axis $(L)$ into five equal lengths.

angiography in a standard manner with a HewlettPackard quartz transducer (1290C) and a HewlettPackard photographic recorder (8890B). A left ventricular angiogram was obtained in the right anterior oblique projection in all subjects. We noted which patients had been receiving treatment with a $\beta$ blocker or a calcium antagonist or both before cardiac catheterisation.

The coronary angiograms, which were reviewed by at least three experienced observers, were all confirmed to be normal. The left ventricular angiograms included in this study were ones in which the left ventricular walls were clearly outlined by contrast material so that silhouettes could be traced. The cycles analysed were sinus beats that did not follow extrasystoles. Left ventricular angiograms suitable for analysis were obtained from 187 patients; left ventricular end systolic and end diastolic volumes and ejection fractions were calculated by means of the single plane area-length

Table 1 Clinical characteristics of groups 1 and 2 and the control group

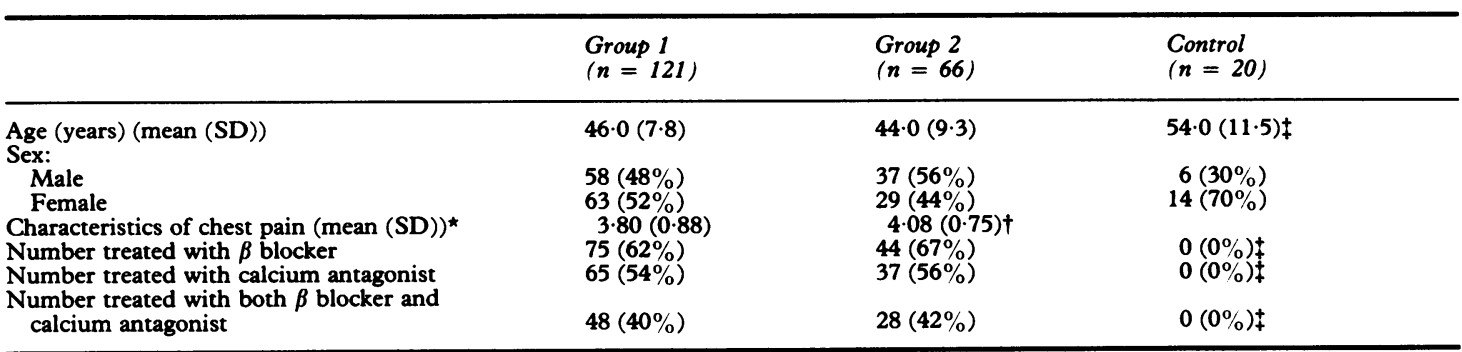

*Presence of characteristic features of chest pain. (Score 0-5.)

+ Significantly different from group $1, \mathrm{p}<0.05$.

+ Significantly different from groups 1 and $2, p<0.01$.

Group 1, patients with no hypokinetic segments.

Group 2, patients with hypokinetic segments. 


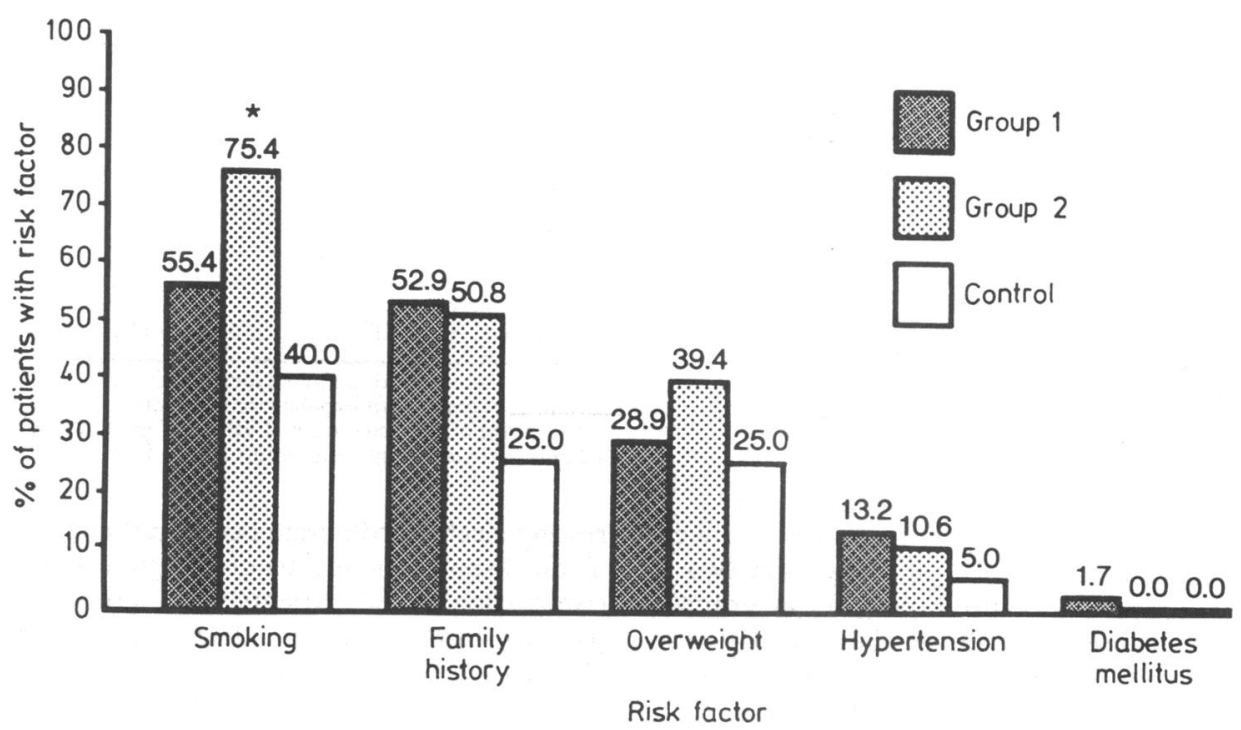

Fig 2 Frequency of five coronary risk factors in patients with no hypokinetic segments (group 1) and patients with hypokinetic segments (group 2) and the control group. ${ }^{\star}$ Significantly different from group 1 and the control group, $p<0.01$.

method after correction for magnification. ${ }^{18}$ Left ventricular regional wall motion was measured by the technique described by Leighton et al. ${ }^{19}$ The outlines of the ventricle at the onset of ejection and at end systole were traced from the projected ventriculogram. A longitudinal axis of the ventricular silhouette on the onset of ejection frame was drawn through the apex so that it divided the ventricle into two equal areas. After correction for rotation, four lines were drawn perpendicularly to the longitudinal axis, dividing the end systolic axis into five equal segments. The percentage of systolic motion in seven hemiaxes $\left(\mathrm{H}_{1-7}, \mathrm{fig} 1\right)$ was calculated and compared with reported normal values. ${ }^{19}$ Regions in which the percentage of systolic motion was <2 SD from the normal mean were defined as being hypokinetic. One hemiaxis $\left(\mathrm{H}_{8}\right.$, fig 1$)$ did not prove useful in defining regional wall motion because of the extreme normal variability in shortening at this site.

A control group was made up of 20 patients who had been investigated because of systolic heart murmurs. None complained of chest pain, all had normal coronary angiograms but they did have trivial aortic valve disease (aortic valve systolic gradient $<20 \mathrm{~mm} \mathrm{Hg}$ ).

We examined the group differences by a one way analysis of variance and compared proportions by the $\chi^{2}$ test.

\section{Results}

Of the 187 patients who had left ventricular angiograms that were suitable for analysis, 121 had no hypokinetic segments (group 1) and 66 had a total of 115 hypokinetic segments (group 2); 39 had one hypokinetic segment, 11 had two, 11 had three, four had four, and one patient had five. Of the 115 hypokinetic segments, 69 occurred on the anterolateral wall $\left(\mathrm{H}_{1-4}\right)$ and 46 on the inferior wall $\left(\mathrm{H}_{5-7}\right)$. Only one of the 20 controls had a hypokinetic segment.

There was no significant difference in age or sex between groups 1 and 2, but their mean age was significantly lower than that of the controls (table 1). In group 2 chest pain was associated with significantly more of the characteristic features than in group $1(p=0.03)$, although chest pain in group 1 was typified by most of the characteristics assessed (table 1). The proportions of patients receiving treatment with a $\beta$ blocker, a calcium antagonist, or a combination of a $\beta$ blocker and a calcium antagonist were not significantly different in groups 1 and 2 (table 1). The dosages of $\beta$ blocker or calcium antagonist administered to the two groups were similar. The mean (SD) dose of atenolol in group 1 (51 patients) was $94 \mathrm{mg}$ (24) $\mathrm{mg}$ daily and in group 2 (26 patients) it was $85 \mathrm{mg}$ (27) $\mathrm{mg}$ daily. The dose of propranolol was $149 \mathrm{mg}$ (55) $\mathrm{mg}$ daily and $160 \mathrm{mg}$ 
Table 2 Resting electrocardiogram of patients in groups 1 and 2 and the control group

\begin{tabular}{llll}
\hline & $\begin{array}{c}\text { Group 1 } \\
(n=121)\end{array}$ & $\begin{array}{l}\text { Group 2 } \\
(n=66)\end{array}$ & $\begin{array}{l}\text { Control } \\
(n=20)\end{array}$ \\
\hline Normal & 83 & 46 & 16 \\
Abnormal: & 38 & 20 & 4 \\
T wave abnormality & 21 & 11 & 3 \\
ST abnormality & 6 & 4 & 0 \\
RBBB & 8 & 3 & 0 \\
LBBB & 3 & 2 & 1 \\
\hline
\end{tabular}

Group 1, patients with no hypokinetic segments.

Group 2, patients with hypokinetic segments.

RBBB, right bundle branch block; LBBB, left bundle branch block. ${ }^{\star} \mathrm{T}$ wave abnormality/ST abnormality. ${ }^{3 \mathrm{~s}}$

(59) $\mathrm{mg}$ daily in groups 1 (15 patients) and 2 (13 patients) respectively. Five patients in group 1 were taking oxprenolol (mean $152 \mathrm{mg}$ daily) and two in group 2 (120 mg daily); three patients in group 1 were taking metoprolol ( $200 \mathrm{mg}$ daily) and two in group 2 (200 $\mathrm{mg}$ daily); and one patient in group 1 was taking sotalol ( $320 \mathrm{mg}$ daily) and one in group 2 ( $320 \mathrm{mg}$ daily). In group 1 (45 patients) the daily dose of nifedipine was $41 \mathrm{mg}$ (14) $\mathrm{mg}$ and in group 2 (24 patients) it was $38 \mathrm{mg}$ (14) mg. Doses of verapamil were $252 \mathrm{mg}(86) \mathrm{mg}$ daily (20 patients) and $268 \mathrm{mg}$ (72) $\mathrm{mg}$ (13 patients) respectively.

Figure 2 shows the details of the presence or absence of the five coronary risk factors investigated in groups 1 and 2 and the control group. There were significantly more smokers in group 2 than in group 1 and the control group ( $p<0.01)$. There was no significant difference, however, in the frequency of the other four risk factors. The total number of risk factors (mean (SD)) per patient, up to a maximum of five, was not significantly different in group $1(1.5$ $(0.9))$ and group $2(1.7(0.9))$, but it was significantly greater in both groups 1 and 2 than in the controls $(1.0(0.8), \mathrm{p}<0.02)$.

The resting electrocardiogram was abnormal in $31 \%$ of patients in group $1,30 \%$ of patients in group 2 , and $20 \%$ of the control group (table 2 ). The commonest abnormality in each group was $T$ wave change, and there was no significant difference in the
Table 3 Results of symptom limited exercise testing in groups 1 and 2

\begin{tabular}{lll}
\hline & $\begin{array}{l}\text { Group 1 } \\
(n=82)\end{array}$ & $\begin{array}{l}\text { Group 2 } \\
(n=44)\end{array}$ \\
\hline ST segment response & & \\
$\quad \begin{array}{l}\text { Normal } \\
\text { Abnormal }\end{array}$ & 33 & 23 \\
$\begin{array}{l}\text { Usual chest pain during test: } \\
\text { Yes }\end{array}$ & 49 & 21 \\
$\quad 34$ & 26 \\
No & 34 & 18 \\
$\quad$ predicted (mean (SD)) & $82.5 \%(32 \cdot 2)$ & $63.5 \%(31 \cdot 1) \dagger$ \\
\hline
\end{tabular}

Group 1, patients with no hypokinetic segments.

Group 2, patients with hypokinetic segments.

$\star$ Percentage of predicted normal value for age and sex. ${ }^{16}$

$\dagger$ Significantly different from group $1, \mathrm{p}<0.01$.

resting electrocardiogram between the three groups. Table 3 shows the results of symptom limited exercise testing in 82 patients from group 1 and 44 patients from group 2. There was no significant difference between groups 1 and 2 in the proportion of patients who had abnormal ST segment response to exercise $(60 \%$ and $48 \%$ respectively). Although $59 \%$ of patients from group 2 developed their usual chest pain on the treadmill compared with only $41 \%$ from group 1, the difference did not reach statistical significance $(p=0.08)$. Exercise duration as a percentage of the predicted normal value was significantly higher $(p<0.01)$ in group $1(82.5$ $(32 \cdot 2) \%$ ) than in group $2(63 \cdot 5(31 \cdot 1) \%)$, indicating that patients with hypokinetic segments had a worse exercise capacity.

Table 4 shows left ventricular volumes and ejection fraction for groups 1 and 2 and the control group. There was no difference in end diastolic volume between the three groups. End systolic volume was significantly higher $(p<0.01)$ and ejection fraction significantly lower $(p<0.001)$ in group 2 than in group 1 and the control group. There was no difference in resting left ventricular end diastolic pressure between group $1(14 \cdot 2(5 \cdot 1) \mathrm{mm} \mathrm{Hg})$ and group $2(14.5(4.7) \mathrm{mm} \mathrm{Hg})$, but in both groups it was significantly higher $(p<0.001)$ than in the control group (10.3 (3.4) $\mathrm{mm} \mathrm{Hg}$ ) (fig 3). Left ventricu-

Table 4 Left ventricular volumes and ejection fraction (mean (SD)) in groups 1 and 2 and the control group

\begin{tabular}{|c|c|c|c|}
\hline & $\begin{array}{l}\text { Group } 1 \\
(n=121)\end{array}$ & $\begin{array}{l}\text { Group 2 } \\
(n=66)\end{array}$ & $\begin{array}{l}\text { Control } \\
(n=20)\end{array}$ \\
\hline $\begin{array}{l}\operatorname{EDV}\left(\mathrm{ml} / \mathrm{m}^{2}\right) \\
\operatorname{ESV}\left(\mathrm{ml} / \mathrm{m}^{2}\right) \\
\operatorname{EF}(\%)\end{array}$ & $\begin{array}{c}122.4(25.2) \\
53.4(13.9) \\
56.4(6.7)\end{array}$ & $\begin{array}{c}126 \cdot 2(27 \cdot 2) \\
68 \cdot 6(17 \cdot 1)^{\star} \\
45 \cdot 8(5 \cdot 8) \dagger\end{array}$ & $\begin{array}{c}130.7(19.4) \\
54.9(11.2) \\
57.8(6.8)\end{array}$ \\
\hline
\end{tabular}

Group 1, patients with no hypokinetic segments.

Group 2, patients with hypokinetic segments.

EDV, left ventricular end diastolic volume; ESV, left ventricular end systolic volume; EF, left ventricular ejection fraction.

* Significantly different from group 1 and control group, $p<0.01$.

+ Significantly different from group 1 and control group, $p<0.001$. 
lar end diastolic pressure was $>15 \mathrm{~mm} \mathrm{Hg}$ in 38 patients $(31 \%)$ from group 1 and in 20 patients $(30 \%)$ from group 2 but in none of the control group.

\section{Discussion}

There has been much debate as to whether patients with angina and normal coronary angiograms experience true myocardial ischaemia. Various theories have been proposed to explain myocardial ischaemia in the absence of coronary occlusive disease. Disease of the small coronary vessels has been suggested, ${ }^{20}$ but histological changes in such vessels have never been found by pathologists in the absence of general vascular disorders. Eliot and Bratt suggested the presence of abnormal haemoglobin-oxygen dissociation characteristics, ${ }^{21}$ but this has not been confirmed by other workers. Richardson et al suggested the possibility of cardiomyopathy on the basis of myocardial biopsy in a small series of cases, ${ }^{11}$ and Boden $e t$ al the possibility that hyperdynamic ventricular contraction increases myocardial oxygen consumption. ${ }^{22}$ More recently it has been shown that some patients with angina and

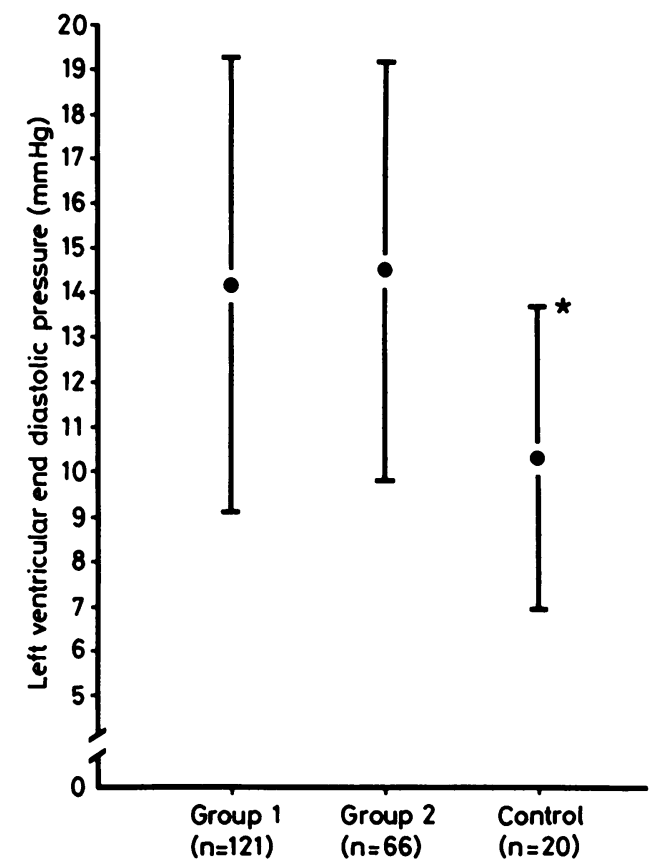

Fig 3 Left ventricular end diastolic pressure in patients with no hypokinetic segments (group 1) and patients with hypokinetic segments (group 2) and the control group.

$\star$ Significantly different from groups 1 and $2, p<0.001$. normal coronary angiograms have decreased coronary vasodilator reserve. ${ }^{10}$

Left ventriculography has not previously been the subject of detailed investigation in a large group of patients with angina and normal coronary angiograms. Objective and subjective analysis of left ventricular angiograms has been examined, ${ }^{23}$ and it was found that reproducibility and accuracy required objective analysis. The use of a quantitative method is essential for the proper interpretation of left ventricular wall motion, and the technique that we used also corrects for descent of the aortic valve and rotation of the apex. ${ }^{19}$

We found that $35 \%$ of patients presenting with angina pectoris who were later found to have normal coronary angiograms had evidence of left ventricular regional wall motion abnormalities. The hypokinetic segments that occurred in these patients were not confined to any particular part of the ventricle. These patients did not have an increased left ventricular end diastolic volume, but they did have a significantly higher left ventricular end systolic volume and a significantly lower left ventricular ejection fraction than patients with normal regional wall motion. Berger et al found left ventricular dysfunction during exercise in $12(39 \%)$ of 31 patients with chest pain, normal coronary arteries, and normal resting left ventricular performance. ${ }^{12}$

In our series there was no difference in resting left ventricular end diastolic pressure between patients with hypokinetic segments and those with normal regional wall motion, but in both groups it was significantly higher than in the control group of patients. A resting left ventricular end diastolic pressure $>15 \mathrm{~mm} \mathrm{Hg}$ was found in $31 \%$ of patients with normal wall motion and $30 \%$ of patients with evidence of hypokinesia. Bush et al found that of 125 patients with angina, normal coronary angiograms, and normal left ventricular ejection fraction, 75 $(60 \%)$ had a resting left ventricular end diastolic pressure $>12 \mathrm{~mm} \mathrm{Hg}$ or a post-angiographic pressure $>22 \mathrm{~mm} \mathrm{Hg}$ or both. ${ }^{24}$ Some of these patients developed chest pain during cardiac catheterisation; this was always associated with a rise in left ventricular end diastolic pressure to $>24 \mathrm{~mm} \mathrm{Hg}$; glyceryl trinitrate consistently produced relief of pain and a fall in pressure to $<12 \mathrm{~mm} \mathrm{Hg}$. They concluded that these patients had isolated left ventricular diastolic dysfunction. Our results showed that of 187 patients presenting with angina who were found to have normal coronary angiograms, $46(24.6 \%)$ had left ventricular systolic dysfunction at rest, $38(20.3 \%)$ had diastolic dysfunction, and $20(10.7 \%)$ had both systolic and diastolic dysfunction.

We found no difference in the resting electrocardiogram or the ST segment response to exercise 
between those patients who had hypokinetic left ventricular segments and those with normal regional wall motion. Exercise capacity as a percentage of the predicted normal value was, however, significantly lower for patients with hypokinetic segments, and these patients were also more likely to develop their usual chest pain during treadmill exercise testing.

Since the work of Richardson et al, ${ }^{11}$ there have been further reports on the findings of right and left ventricular endomyocardial biopsy in small numbers of patients with angina and normal coronary angiograms. ${ }^{25-27}$ Histological abnormalities have been reported in $48-100 \%$ of cases. Patients with congestive cardiomyopathy often complain of chest pain, despite the presence of normal or even large coronary arteries, and they have been found to have reduced coronary blood flow at rest and during cardiac pacing. ${ }^{28}$ No patient in our series had clinical or radiological evidence of cardiac failure. The cause of left ventricular dysfunction in some patients in this study remains uncertain, but there was a higher incidence of smoking in those with regional wall motion abnormalities. Hartz et al have suggested that smoking is associated with a cardiomyopathy and that the relation is separate from the association of smoking with coronary artery disease. ${ }^{29}$

Although the prognosis of patients with chest pain and normal coronary arteries has been believed to be benign, ${ }^{230-34}$ many previous studies have excluded patients with abnormal left ventricular angiograms $^{23031}$ and have included patients with atypical chest pain. ${ }^{31-33}$ Our findings of mild left ventricular dysfunction in a considerable proportion of patients with typical angina pectoris and normal coronary angiograms raise the possibility that the prognosis in terms of persistence of symptoms and mortality in these patients with left ventricular abnormality may not prove to be as good as has been previously suggested, although currently we do not have any evidence for this.

We thank Dr C L Bray and Dr C Ward for allowing us to study patients under their care. The work described is part of a study submitted by PMS to the University of Manchester for the degree of doctor of medicine.

\section{References}

1 Proudfit WL, Shirey EK, Sones FM. Selective cine coronary arteriography: correlation with clinical findings in 1000 patients. Circulation 1966;33: 901-10.

2 Kemp HG, Vokonas PS, Cohn PF, Gorlin R. The anginal syndrome associated with normal coronary arteriograms: report of a six year experience. $A m \mathcal{F}$ Med 1973;54:735-42.
3 Benjamin SB, Castell DO. Chest pain of esophageal origin. Arch Intern Med 1983;143:772-6.

4 Davies HA, Jones DB, Rhodes J. "Oesophageal angina" as the cause of chest pain. $\mathscr{f} A M A$ 1982;248:2274-8.

5 Bass C, Wade C, Hand D, Jackson G. Patients with angina with normal and near normal coronary arteries: clinical and psychological state 12 months after angiography. $\mathrm{Br} \mathrm{Med} \mathcal{F}$ 1983;287:1505-8.

6 Bemiller CR, Pepine CJ, Rogers AK. Long-term observations in patients with angina and normal coronary arteriograms. Circulation 1973;47:36-43.

7 Borer JS, Brensike JF, Redwood DR, et al. Limitations of the electrocardiographic response to exercise in predicting coronary artery disease. $N$ Engl $\mathcal{F}$ Med 1975;293:367-71.

8 Arbogast R, Bourassa MG. Myocardial function during atrial pacing in patients with angina pectoris and normal coronary arteriograms. Comparison with patients having significant coronary artery disease. Am f Cardiol 1973;32:257-63.

9 Boudoulas H, Cobb TC, Leighton RF, Wilt SM. Myocardial lactate production in patients with angina-like chest pain and angiographically normal coronary arteries and left ventricle. $A m \quad \mathcal{f}$ Cardiol 1974;34:501-5.

10 Opherk D, Zebe H, Weihe E, et al. Reduced coronary dilatory capacity and ultrastructural changes of the myocardium in patients with angina pectoris and normal coronary arteriograms. Circulation 1981;63: 817-25.

11 Richardson PJ, Livesley B, Oram S. Angina pectoris with normal coronary arteries. Transvenous myocardial biopsy in diagnosis. Lancet 1974;ii:677-80.

12 Berger HJ, Sands MJ, Davies RA, et al. Exercise left ventricular performance in patients with chest pain, ischaemic-appearing exercise electrocardiograms, and angiographically normal coronary arteries. Ann Intern Med 1981;94:186-91.

13 Berger BC, Abramowitz R, Park CH, et al. Abnormal thallium-201 scans in patients with chest pain and angiographically normal coronary arteries. $\mathrm{Am} \mathfrak{J}$ Cardiol 1983;52:365-70.

14 Ramsdale DR, Bennett DH, Bray CL, Ward C, Beton DC, Faragher EB. Angina, coronary risk factors and coronary artery disease in patients with valvular disease. A prospective study. Eur Heart $\mathcal{f}$ 1984;5:716-26.

15 Metropolitan Life Insurance Company. Metropolitan height and weight tables. 1983.

16 Bruce RA, Kusumi F, Hosmer D. Maximal oxygen intake and nomographic assessment of functional aerobic impairment in cardiovascular disease. $\mathrm{Am}$ Heart $\mathcal{F}$ 1973;85:546-62.

17 Meller J, Goldsmith SJ, Rudin A, et al. Spectrum of exercise thallium-201 myocardial perfusion imaging in patients with chest pain and normal coronary angiograms. Am $\mathcal{f}$ Cardiol 1979;43:717-23.

18 Rackley CE. Quantitative evaluation of left ventricular function by radiographic techniques. Circulation 1976;54:862-79.

19 Leighton RF, Wilt SM, Lewis RP. Detection of hypo- 
kinesis by a quantitative analysis of left ventricular cineangiograms. Circulation 1974;50:121-7.

20 Selzer A. Cardiac ischaemic pain in patients with normal coronary arteriograms. Am $\mathcal{f}$ Med 1977;63: 661-5.

21 Eliot RS, Bratt G. The paradox of myocardial ischaemia and necrosis in young women with normal coronary arteriograms. Relation to abnormal haemoglobin-oxygen dissociation. $\mathrm{Am} \mathcal{f}$ Cardiol 1969;23:633-8.

22 Boden WE, Smulyan H, Potts J, Johnson LW, Obeid AI, Eich RH. Left ventriculography in patients with the angina syndrome and normal coronary arteriograms [Abstract]. Am $\mathcal{F}$ Cardiol 1974;33:127.

23 Chaitman BR, DeMots H, Bristow JD, Rosch J, Rahimtoola SH. Objective and subjective analysis of left ventricular angiograms. Circulation 1975;52: 420-5.

24 Bush CA, Fanning W, Kolibash AJ, Leier CV. Elevated left ventricular filling pressure as a cause of angina in patients with normal coronary arteries [Abstract]. Am $\mathcal{F}$ Cardiol 1982;49:950.

25 Opherk D, Zebe H, Weihe E, et al. Reduced coronary reserve and ultrastructural changes of the myocardium in patients with angina pectoris but normal coronary arteries [Abstract]. Circulation 1979;59: II-75.

26 Losse B, Kuhn H, Kronert H, Rafflenbeul D, Feinendegen LE, Loogen F. Exercise thallium-201 myocardial perfusion imaging in patients with nor$\mathrm{mal}$ coronary angiogram and ventriculogram [Abstract]. Circulation 1979;59:II-148.

27 Richardson PJ, Atkinson L, Olsen E, Jackson G.
Angina with normal coronary arteriograms; a metabolic and histopathological evaluation [Abstract]. Circulation 1979;59:II-179.

28 Pasternac A, Noble J, Streulens Y, Elie R, Henschke C, Bourassa MG. Pathophysiology of chest pain in patients with cardiomyopathies and normal coronary arteries. Circulation 1982;65:778-89.

29 Hartz AJ, Anderson AJ, Brooks HL, Manley JC, Parent GT, Barboriak JJ. The association of smoking with cardiomyopathy. $N$ Engl $f$ Med 1984;311: 1201-6.

30 Ockene IS, Shay MJ, Alpert JS, Weiner BH, Dalen JE. Unexplained chest pain in patients with normal coronary arteriograms. $N$ Engl $\mathcal{F}$ Med 1980;303:1249-52.

31 Day LJ, Sowton E. Clinical features and follow-up of patients with angina and normal coronary arteries. Lancet 1976;ii:334-7.

32 Waxler EB, Kimbiris D, Dreifus LS. The fate of women with normal coronary arteriograms and chest pain resembling angina pectoris. $A m \mathcal{F}$ Cardiol 1971;28:25-32.

33 Pasternak RC, Thibault GE, Savoia M, DeSanctis RW, Hutter AM. Chest pain with angiographically insignificant coronary arterial obstruction. Clinical presentation and long-term follow up. Am $\mathcal{F}$ Med 1980;68:813-7.

34 Proudfit WL, Bruschke AV, Sones FM. Clinical course of patients with normal or slightly or moderately abnormal coronary arteriograms: 10 year follow-up of 521 patients. Circulation 1980;62:712-7.

35 International Business Machines Corporation. Health care support/electrocardiogram analysis program, physician's guide. 2nd ed. New York, 1974:27-9. 